\title{
MYO6 knockdown inhibits the growth and induces the apoptosis of prostate cancer cells by decreasing the phosphorylation of ERK1/2 and PRAS40
}

\author{
DONG WANG $^{1 *}$, LIBING ZHU $^{2 *}$, MIN LIAO $^{3 *}$, TENGYUE ZENG $^{3}$, WENLI ZHUO $^{3}$, \\ SHUNLIANG YANG ${ }^{3}$ and WEIZHEN WU ${ }^{1}$ \\ ${ }^{1}$ Department of Urology, Fuzhou Dongfang Hospital, Xiamen University, Xiamen 361005; \\ ${ }^{2}$ Department of Urology, Lushan Sanatorium of the PLA, Lushan 332000; \\ ${ }^{3}$ Department of Urology, Fuzhou General Hospital, Fujian Medical University, Fuzhou, Fujian 350025, P.R. China
}

Received August 18, 2015; Accepted January 8, 2016

DOI: $10.3892 / o r .2016 .4910$

\begin{abstract}
Prostate cancer is the second most frequently diagnosed cancer among males around the world. Myosin VI (MYO6), as a motor protein, has been reported to be implicated in cancer-related cell migration and cellular functions. To investigate the role of MYO6 in prostate cancer, immunohistochemical analysis was firstly applied to prostate cancer tissues and revealed that MYO6 was closely related with the Gleason score in prostate cancer. Then we used specific short hairpin RNA (shRNA) to downregulate MYO6 expression in DU145 and PC-3 cells and found that decreased MYO6 expression significantly suppressed cell proliferation, as determined by MTT and colony formation assays. Flow cytometry confirmed that the suppression of MYO6 promoted cell cycle arrest at the G2/M and sub-G1 phase in the DU145 cells. Furthermore, PathScan intracellular signaling array analysis demonstrated that the phosphorylation of ERK1/2 and PRAS40 was downregulated in the DU145 cells following MYO6 knockdown. Knockdown of MYO6 downregulated the expression of AKT3 and upregulated the expression of PARP, as confirmed by western blot analysis. These results suggest that MYO6 plays an essential role in the progression of prostate cancer and silencing of MYO6 may be a promising therapeutic approach for prostate cancer.
\end{abstract}

\section{Introduction}

Prostate cancer is the second leading cause of cancer-related mortality in males, and the incidence has been rising rapidly worldwide, including the incidence in low-risk popula-

Correspondence to: Dr Weizhen Wu, Department of Urology, Fuzhou General Hospital, 156 Xi'erhuan North Road, Fuzhou, Fujian 350025, P.R. China

E-mail: weizhenwu0101@163.com

*Contributed equally

Key words: prostate cancer, MYO6, cell proliferation, ERK1/2, PRAS40 tions $(1,2)$. The etiological factors for prostate cancer include genetic changes, sex hormones, diet and environment $(3,4)$. Based on prostate cancer pathogenesis and characteristics, various advanced strategies have been applied in clinical practice. However, deleterious side effects frequently occur and make current strategies ineffective against stage T3 prostate cancer (5). Therefore, exploring effective management strategies and identifying therapeutic targets are urgently needed for the treatment of prostate cancer.

Myosins are motor proteins that move along cytoskeletal filaments by using energy derived from ATP (6,7). Myosins constitute a superfamily of more than 18 known members (8). Myosin VI (MYO6) is a member of the unconventional myosin protein, which moves towards the minus ends of polarized actin filaments in the opposite direction to all other myosins. Previous studies indicate that it can promote cancer-related cell migration and cellular functions (9-11). For instance, the in vitro migration and colony formation were impaired in LNCap human prostate cancer cells after MYO6 knockdown (12). The cell spreading and migration of high-grade ovarian carcinoma cells were impeded by knockdown of MYO6 (13). The overexpression of cancer-specific MYO6 has been shown primarily restricted in human prostate and breast cancers (12). In addition, MYO6 was shown to regulate protein secretion in prostate cancer cells (14).

To explore the relationship between MYO6 and prostate cancer, the association among MYO6 expression profiles with clinical and pathological features of prostate cancer was analyzed. Then, lentivirus-based shRNA was used to efficiently knock down the expression of MYO6 in prostate cancer DU145 and PU-3 cells. We aimed to investigate its possible function to impact growth in prostate cancer cells in vitro.

\section{Materials and methods}

Immunohistochemistry. A total of 148 cases of prostate cancer tissues used in this research were biopsy samples obtained from Fuzhou General Hospital of the Nanjing Military Command (Fuzhou, China). Immunohistochemistry was carried out as previously described (15) using Histostain-Plus 3rd Gen IHC 
Detection kit (85-9073; Invitrogen). Following fixation with $100 \%$ acetone and quenching of endogenous peroxidase, the samples were blocked with $2 \%$ normal goat serum (dilution 1:300, M0691; Sigma). Then the samples were incubated with mouse anti-MYO6 mouse (dilution 1:50, SC-50461; Santa Cruz Biotechnology), washed with PBS and incubated with biotinylated goat anti-mouse IgG secondary antibody. Finally, the staining intensity was scored visually and recorded as follows: - for negative, -+ for slightly positive,+ for moderately positive and ++ for strongly positive immunoreactivity.

Cell culture. The prostate cancer cell lines DU145 and PC-3 and human embryonic kidney cell line 293 (HEK293) were purchased from the Cell Bank of the Chinese Academy of Science (Shanghai, China). DU145 cells were cultured in Ham's F-12 (\#11765-054; Gibco-BRL) medium containing 10\% fetal bovine serum (FBS, \#S1810; Biowest) and 1\% non-essential amino acids (NEAA). PC-3 cells were plated in Ham's F-12 supplemented with $10 \%$ FBS. HEK293T cells were grown in Dulbecco's modified Eagle's medium (DMEM, SH30243.01; Hyclone) with $10 \%$ FBS. Cells were maintained in a humidified atmosphere with air containing $5 \% \mathrm{CO}_{2}$ at $37^{\circ} \mathrm{C}$.

Lentiviral plasmid construction. Three segments of MYO6 (NCBI accession no. NM_004999) targeted by shRNA were designed by siRNA-designing software. The sequences of the shRNA targets were 5'-GTGAATCCAGAGATAAGTTTACT CGAGTA A ACTTATCTCTGGATTCACTTTTT-3' for MYO6 shRNA s1 and 5'-CCAGATTTAACCATTCCATAACT CGAGTTATGGAATGGTTAAATCTGGTTTTTT-3' for MYO6 shRNA s2. The control shRNA sequence was 5'-GCG GAGGGTTTGAAAGAATATCTCGAGATATTCTTTCAA ACCCTCCGCTTTTTT-3'. Three nucleotide sequences were cloned into the pFH-L lentiviral vector (Shanghai Hollybio, China), respectively. For lentivirus packaging, the HEK293T cells were transfected with pFH-L-MYO6 shRNA s1, pFH-LMYO6 shRNA s2, or control shRNA with virion-packaging elements (pVSVG-I and pCMVAR8.92; Shanghai Hollybio) using Lipofectamine 2000 (Invitrogen) to generate three groups shMYO6 (S1), shMYO6 (S2) and shCon. Forty-eight hours later, the supernatant was collected and the lentiviral vector particles were harvested by centrifugation $(4,000 \mathrm{xg}$, $10 \mathrm{~min}$ at $4^{\circ} \mathrm{C}$ ). Then, the particles were filtered through a $45-\mu \mathrm{m}$ filter and the viral concentrate was collected by filtrate centrifuged for $20 \mathrm{~min}$ at $4,000 \mathrm{xg}$ at $4^{\circ} \mathrm{C}$.

Quantitative real-time PCR ( $q R T-P C R)$ analysis. Total RNA was extracted from cells using TRIzol reagent (Gibco-BRL). Primers for MYO6 (forward, AATCACTGGCTCACATGCAG and reverse, AATGCGAGGTTTGTGTCTCC) and actin (forward, GTGGACATCCGCAAAGAC and reverse, AAAGGGTGTAACGCAACTA) were designed to evaluate mRNA expression of MYO6 on BioRad Connet Real-Time PCR platform (Bio-Rad, Hercules, CA, USA). Each $20 \mu 1$ reaction contained 2X SYBR Premix Ex Taq $10 \mu \mathrm{l}$, forward and reverse primers $(2.5 \mu \mathrm{M}) 0.8 \mu \mathrm{l}$, cDNA5 $\mu \mathrm{l}$, and $\mathrm{dd}_{2} \mathrm{O} 4.2 \mu \mathrm{l}$. The qPCR procedures were as followed: initial denaturation for $1 \mathrm{~min}$ at $95^{\circ} \mathrm{C}$, denaturation for $5 \mathrm{sec}$ at $95^{\circ} \mathrm{C}$, and annealing for 40 cycles at $60^{\circ} \mathrm{C}$. Relative expression of $M Y O 6$ mRNA was calculated by using the $2^{-\Delta \Delta \mathrm{Ct}}$ method.
Western blot assay. Lentivirus-transduced cells were washed twice with ice-cold PBS and lysed in 2X SDS sample buffer (10 mM EDTA, 4\% SDS, $10 \%$ glycine in $100 \mathrm{mM}$ Tris- $\mathrm{HCl}$ buffer, $\mathrm{pH}$ 6.8) at $4^{\circ} \mathrm{C}$. Cell proteins were separated by SDS-PAGE and transferred to polyvinylidene difluoride membranes (Millipore, Bedford, MA, USA). The membranes were blocked by $4 \%$ nonfat dry milk and incubated with mouse anti-MYO6 (1:1,000 dilution, cat \#M0691; Sigma), rabbit anti-Akt3 (1:500 dilution, 21641-1-AP; Proteintech), rabbit anti-PARP (1:1,000 dilution, \#9542; Cell Signaling Technology), rabbit anti-GAPDH (1:100,000 dilution, 10494-1AP) and mouse anti- $\beta$-actin $(1: 2,000$ dilution, 60008-1-1g) (both from Proteintech). After washing in PBS with $0.05 \%$ Tween-20, the membranes were incubated with horseradish peroxidase (HRP)-conjugated goat anti-mouse (1:5,000 dilution, SC-2005) and HRP-conjugated goat anti-rabbit (1:5,000 dilution, SC-2054) (both from Santa Cruz Biotechnology), respectively. MYO6 protein was visualized by enhanced chemiluminescence (ECL; Amersham) according to the manufacturer's protocol.

MTT assay. Tetrazolium (MTT) colorimetric assay was used to measure cell viability and activity. DU145 and PC-3 cells were plated at a concentration of 3,000 cells/dish and 2,000 cells/ dish in 96-well plates. Afterwards, DU145 and PC-3 cells were infected by the lentivirus encoding MYO6 shRNA or the control shRNA for $96 \mathrm{~h}$. Then, $20 \mu \mathrm{l}$ MTT solution (stock solution $5 \mathrm{mg} / \mathrm{ml}$ PBS) was added to each well and incubated for $5 \mathrm{~h}$ at $37^{\circ} \mathrm{C}$. The MTT-containing medium was then removed, and $150 \mu \mathrm{l}$ DMSO was added to each tube. The optical density at $595 \mathrm{~nm}$ was detected using a microplate reader (Bio-Rad).

Colony-forming capability analysis. DU145 and PC-3 cells transfected with shMYO6 (S1) and shCon were grown in 6-well plates at a density of 500 cells/well and incubated for 8 and 9 days, respectively. The medium was replaced every 2-3 days until 8-9 days in culture of the DU145 and PC-3 cells, and then the cells were washed in PBS before being fixed in 4\% paraformadehyde for $10 \mathrm{~min}$. After treatment, the cells were stained with crystal violet $(0.5 \%$ crystal violet in $20 \%$ methanol) for $20 \mathrm{~min}$. A fluorescence microscope (Zeiss) was used to detect cell colonies. The result showed that more than 50 cells were counted per colony.

Analysis of the cell cycle distribution of prostate DU145 cells. To investigate cell cycle distribution, flow cytometry of propidium iodide (PI) staining was carried out. After infection with shMYO6 (S1) or shCon for 5 days, the DU145 cells were then adjusted to a concentration of $2 \times 10^{6}$ cells/dish in 6-cm dishes and cultured for $40 \mathrm{~h}$ at $37^{\circ} \mathrm{C}$. After being washed with ice-cold PBS, the cells were fixed with $1 \mathrm{ml}$ of $70 \%$ cold alcohol and kept at $4^{\circ} \mathrm{C}$ for $20 \mathrm{~min}$. The supernatant was discarded by centrifugation, resuspended in a mixture of $1 \mathrm{ml}$ PI $(10 \mu \mathrm{g} / \mathrm{ml})$ and DNase-free RNase $(20 \mu \mathrm{g} / \mathrm{ml})$ and incubated for $20 \mathrm{~min}$. The cell cycle progression was analyzed by flow cytometry (FACSCalibur; Becton Dickinson) after the sample was filtered through a $50-\mu \mathrm{m}$ nylon mesh.

Detection of intracellular signaling. To stimultaneously detect 18 vital and well-characterized signaling molecules, 


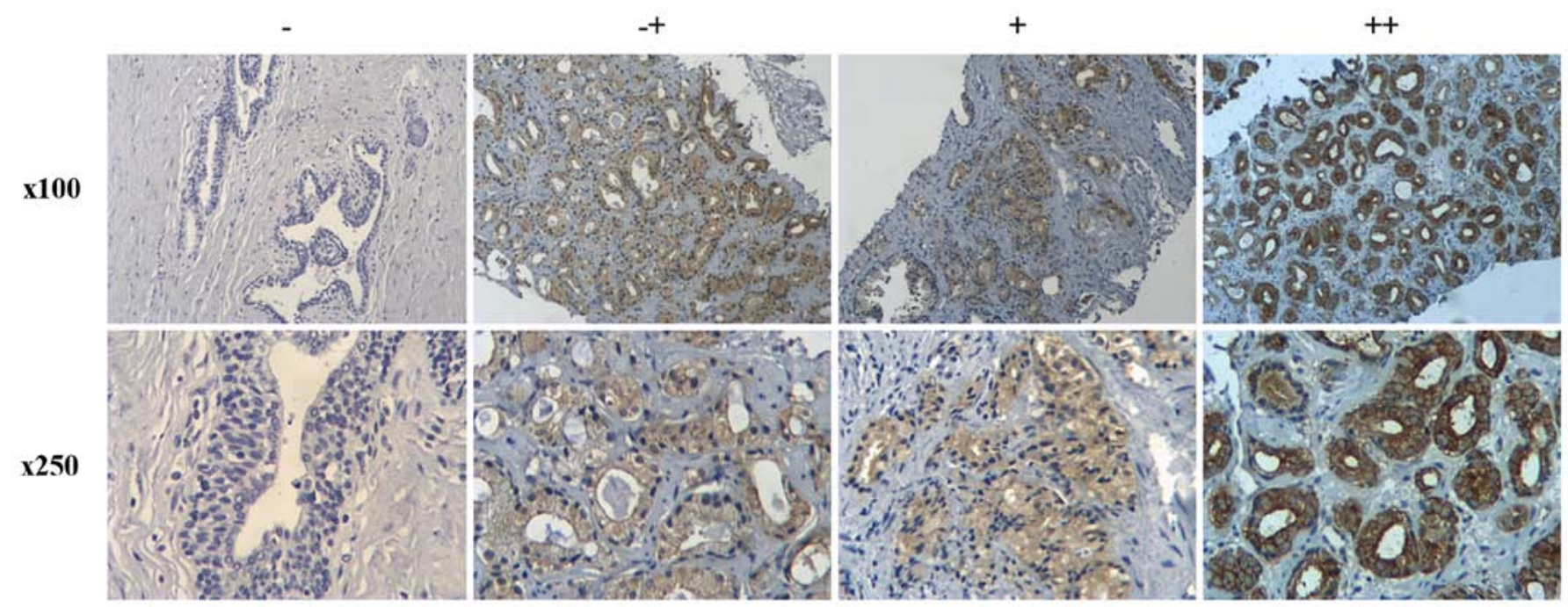

Figure 1. MYO6 expression in the cytoplasm of prostate cancer cells. Immunohistochemistry shows $M Y O 6$ expression in the cytoplasm of prostate cancer tissues with negative (-), slightly positive (-+), positive (+), and strong positive (++) MYO6 immunoreactivity. Magnification, x100 and x250.

the cell lystates were analyzed by PathScan ${ }^{\circledR}$ Intracellular Signaling Array kit according to the manufacturer's instructions. After infection with shMYO6 (S1) or shCon for 5 days, the DU145 cells were rinsed twice with ice-cold 1X PBS and immediately dissolved in $1 \mathrm{X}$ cell lysis buffer. Array Blocking Buffer was then added to each sample and blocked for $20 \mathrm{~min}$. An equal volume of lysate was placed in each samples and incubated for $2 \mathrm{~h}$ at room temperature. Before incubation with HRP-linked streptavidin, each reaction was incubated with detective antibody mixture for $1 \mathrm{~h}$ at room temperature. The slides were exposed to film for $25 \mathrm{sec}$ after being developed with LumiGLO/Peroxide reagent (Cell Signaling Technology).

Statistical analysis. Statistical analysis was carried out using SPSS 13.0 software. Each experiment was performed at least three times, and the results are presented as mean \pm SD. Student's t-test was used to detect the significance of the differences $(\mathrm{P}<0.05)$ between the experimental and control groups.

\section{Results}

Expression of MYO6 in prostate cancer and normal prostate tissues. Immunohistochemistry was used to clarify the expression of MYO6 in prostate cancer. Representative images of four degrees of MYO6 expression intensity are shown in Fig. 1. The association between MYO6 expression and the clinicopathologic parameters are shown in Table I. Higher expression of MYO6 was found to be significantly related with Gleason score $(\mathrm{P}<0.01)$. However, there was no significantly difference between MYO6 expression and patient age.

Expression of MYO6 is significantly suppressed in prostate cancer cells after infection with shMYO6 (S1). To study the potential relationship between MYO6 levels and prostate cancer risk, the expression of MYO6 was knocked down in DU145 and PC-3 cells using lentiviral-mediated RNA inter-
Table I. Expression of MYO6 is positively correlated with pathological grade in the prostate cancer tissues $(n=148)$.

\begin{tabular}{|c|c|c|c|c|c|c|}
\hline \multirow{2}{*}{$\begin{array}{l}\text { Clinical pathologic } \\
\text { parameters }\end{array}$} & \multirow[b]{2}{*}{ Total } & \multicolumn{4}{|c|}{ Expression of MYO6 } & \multirow[b]{2}{*}{ P-value } \\
\hline & & - & $-\sim+$ & + & ++ & \\
\hline Age (years) & & & & & & 0.2876 \\
\hline$\leq 70$ & 58 & 7 & 11 & 33 & 7 & \\
\hline$>70$ & 90 & 8 & 17 & 61 & 4 & \\
\hline Gleason score & & & & & & 0.0059 \\
\hline I (2-4) & 10 & 1 & 5 & 4 & 0 & \\
\hline II (5-6) & 25 & 6 & 7 & 10 & 2 & \\
\hline III (7-10) & 113 & 8 & 16 & 80 & 9 & \\
\hline
\end{tabular}

ference. As shown in Fig. 2A, most of the cells presented GFP-positive signals suggesting satisfactory infection efficacy for shMYO6 (S1). Then the knockdown efficacy was further determined in the DU145 and PC-3 cells using qRT-PCR and western blot analysis. Levels of MYO6 mRNA were found to be much lower in the DU145 and PC-3 cells after infection with shMYO6 (S1) than that in the shCon-transfected cells (Fig. 2B and $\mathrm{C}, \mathrm{P}<0.001$ ). A further examination of MYO6 protein expression was performed in the DU145 and PC-3 cells following shMYO6 (S1) and shCon infection. Western blot analysis also showed that MYO6 protein was reduced following MYO6 knockdown (Fig. 2D and E). These results suggest that shMYO6 (S1) significantly downregulated MYO6 expression in the DU145 and PC-3 cells.

\section{Knockdown of MYO6 by shMYO6 (S1) inhibits the proliferation} of prostate cancer cells. An MTT assay was used to determine the effect of MYO6 knockdown on cell proliferation. As shown in Fig. 3A, the growth curve of the shMYO6 (S1)-treated cells started to decrease from day 2 , compared with the shCon- 
A

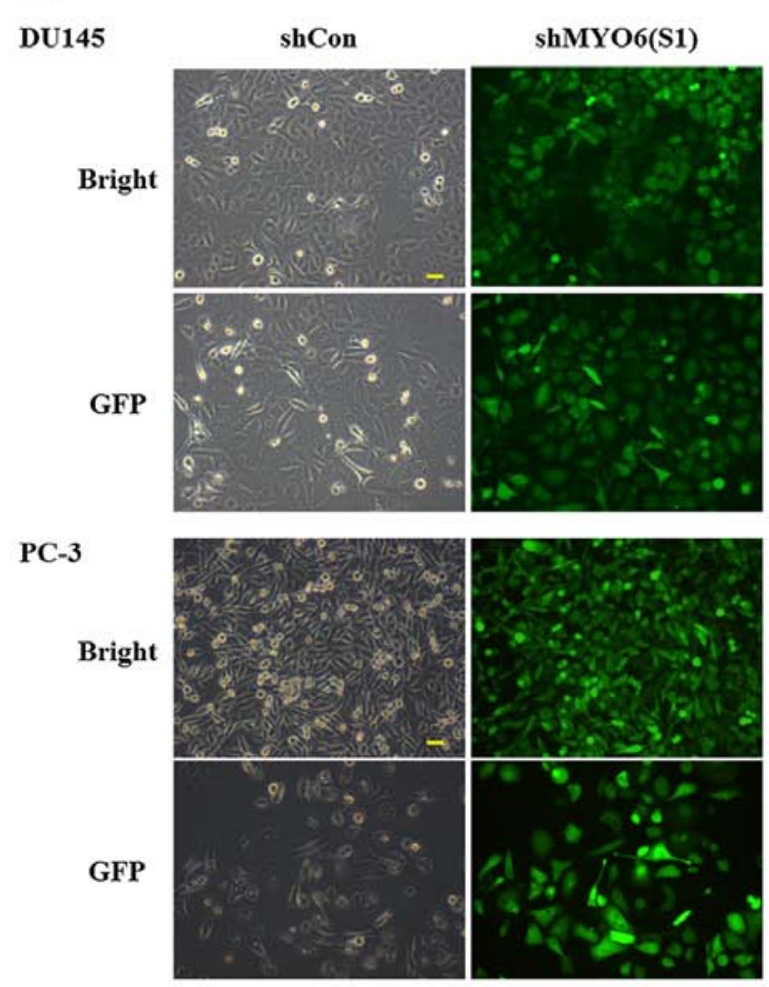

B

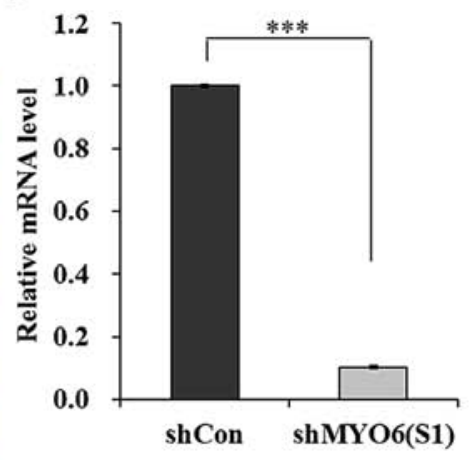

C

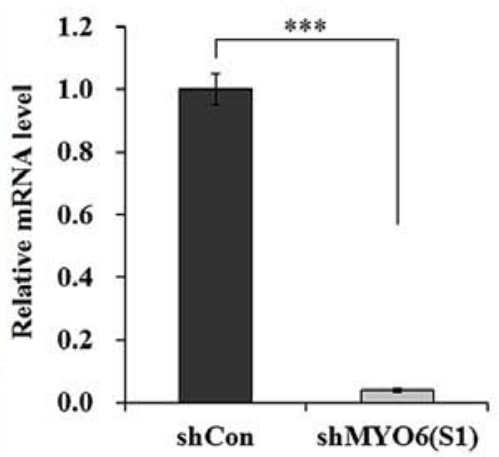

D

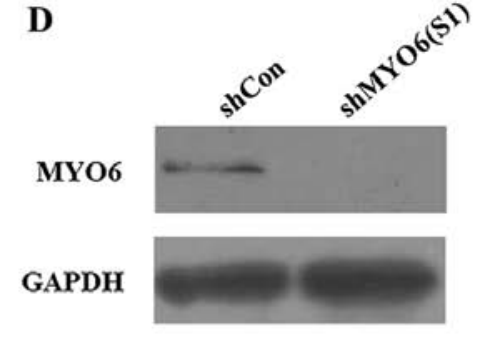

$\mathbf{E}$

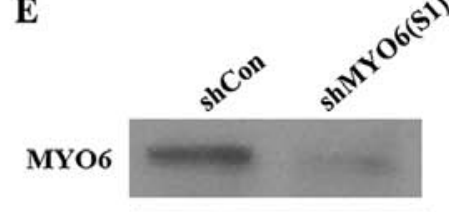

GAPDH

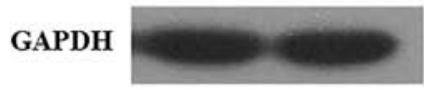

Figure 2. The lentivirus expressing shMYO6 (S1) effectively decreases MYO6 mRNA and protein levels in the prostate cancer cells. (A) Representive images of DU145 and PC-3 cells infected with shMYO6 (S1) and shCon for $96 \mathrm{~h}$. GFP fluorescence indicated efficiency of the lentivirus infection. (B and C) MYO6 mRNA levels were significantly decreased in the shMYO6 (S1)-infected cells as measured by qRT-PCR. ${ }^{* * *} \mathrm{P}<0.001$. (D and E) Western blot analysis indicated that the MYO6 protein levels were obviously downregulated in the cells with shMYO6 (S1) infection.

treatedcells in the DU145 and PC-3 cells. The decline reached 83.3\% $(\mathrm{P}<0.001)$ and $19.8 \%(\mathrm{P}<0.001)$ on day 5 in the DU145 and PC-3 cells, respectively, compared with the shCon-treated cells. These data indicate that shMYO6 (S1)-mediated MYO6 knockdown obviously suppressed the proliferation of the DU145 and PC-3 cells.

Then, the long-term effect of MYO6 silencing on cell proliferation was determined by colony formation assay. As shown in Fig. 3B, there were fewer and smaller colonies in the shMYO6 (S1)-treated cells than those in the shCon-treated cells. Moreover, statistical analysis further confirmed that the number of colonies that formed in the cells was significantly decreased in the shMYO6 (S1)-treated cells (Fig. 3C, $\mathrm{P}<0.001)$. The results showed that MYO6 knockdown mediated by shMYO6 (S1) markedly inhibited the cell proliferation of the DU145 and PC-3 cells.

Knockdown of MYO6 by shMYO6 (S2) suppresses the proliferation of prostate cancer cells. The knockdown efficiency of MYO6 by the other recombinant lentivirus shMYO6 (S2) was determined in DU145 cells. After four days of infection, more than $90 \%$ of the DU145 cells strongly expressed GFP fluorescence (Fig. 4A). In addition, the mRNA and protein levels of MYO6 were significantly downregulated in the shMYO6 (S2)-treated DU145 cells (Fig. 4B). MTT assay showed that cell viability was significantly decreased in the shMYO6 (S2)-treated DU145 cells $(\mathrm{P}<0.001)$, compared with the cell viability of the shCon-treated cells (Fig. 4C).
Knockdown of MYO6 arrests DU145 cells at the G2/M phase and sub-G1 phase. In order to investigate the mechanisms underlying the growth suppressive effect of MYO6 knockdown, the cell cycle distribution of DU145 cells was analyzed using flow cytometric analysis (Fig. 5A). As shown in Fig. 5B, the percentage of cells in G0/G1 was significantly decreased whereas the percentage of cells in the G2/M phase was markedly increased in the shMYO6 (S1)-treated cells compared with those in the shCon-treated cells $(\mathrm{P}<0.001)$. Notably, more cells were accumulated in sub-G1 phase, representing early apoptosis in the shMYO6 (S1)-treated cells compared with the number of cells in the shCon-treated cells (Fig. 5C, $\mathrm{P}<0.001$ ). These data suggest that MYO6 knockdown suppresses prostate cancer cell growth via blockade of cell cycle progression.

MYO6 knockdown inhibits ERK1/2, AKT3, PRAS40 and $P A R P$ activation. To further explore the molecular mechanisms underlying MYO6-mediated prostate cancer cell growth, PathScan ${ }^{\circledR}$ Intracellular Signaling Array kit was used to detect the modifications of signaling molecules in the shMYO6 (S1)-treated DU145. As shown in Fig. 6A, the phosphorylated levels of ERK1/2 (Thr202/Tyr204) and PRAS (Thr246) were downregulated in the shMYO6 (S1)-treated cells compared with levels in the shCon-treated cells. Moreover, the expression of AKT3, as a downstream effector molecule of ERK-1/2 and PRAS40, was slightly downregulated in the shMYO6 (S1)-treated cells. Apoptosis marker PARP presented higher expression in the shMYO6 
A

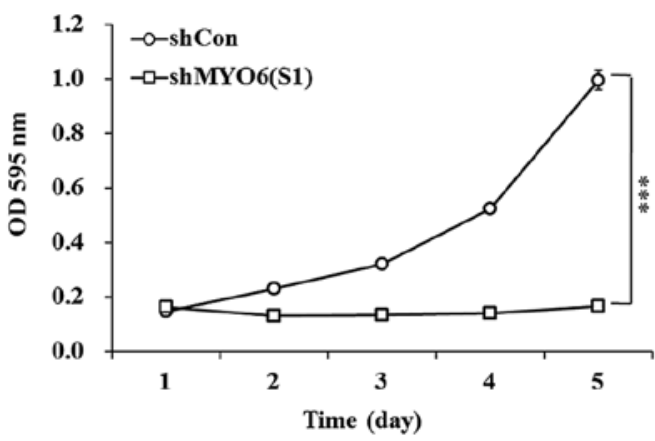

PC-3

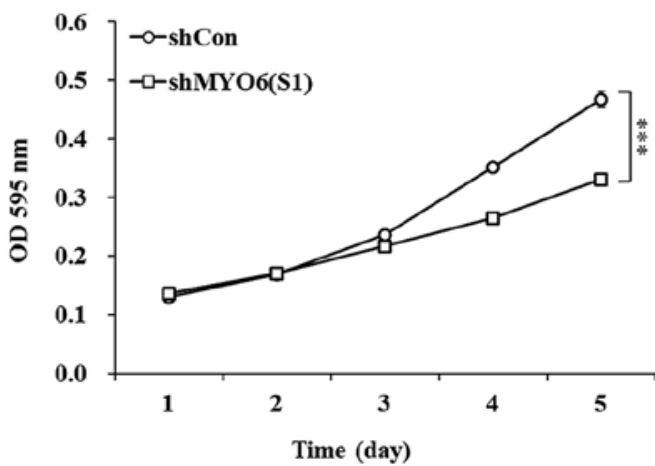

B

\begin{tabular}{lr} 
DU145 \\
\hline shCon & shMYO6(S1)
\end{tabular}

Crystal violet

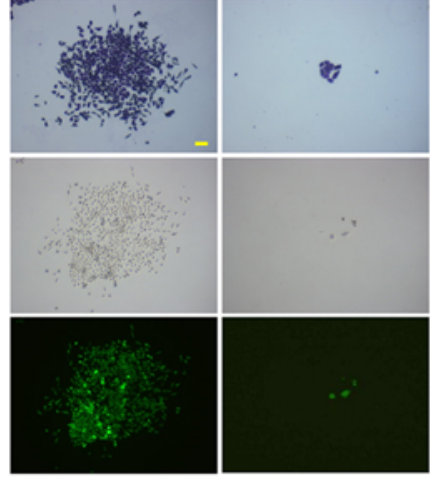

Bright field

Fluorescent field
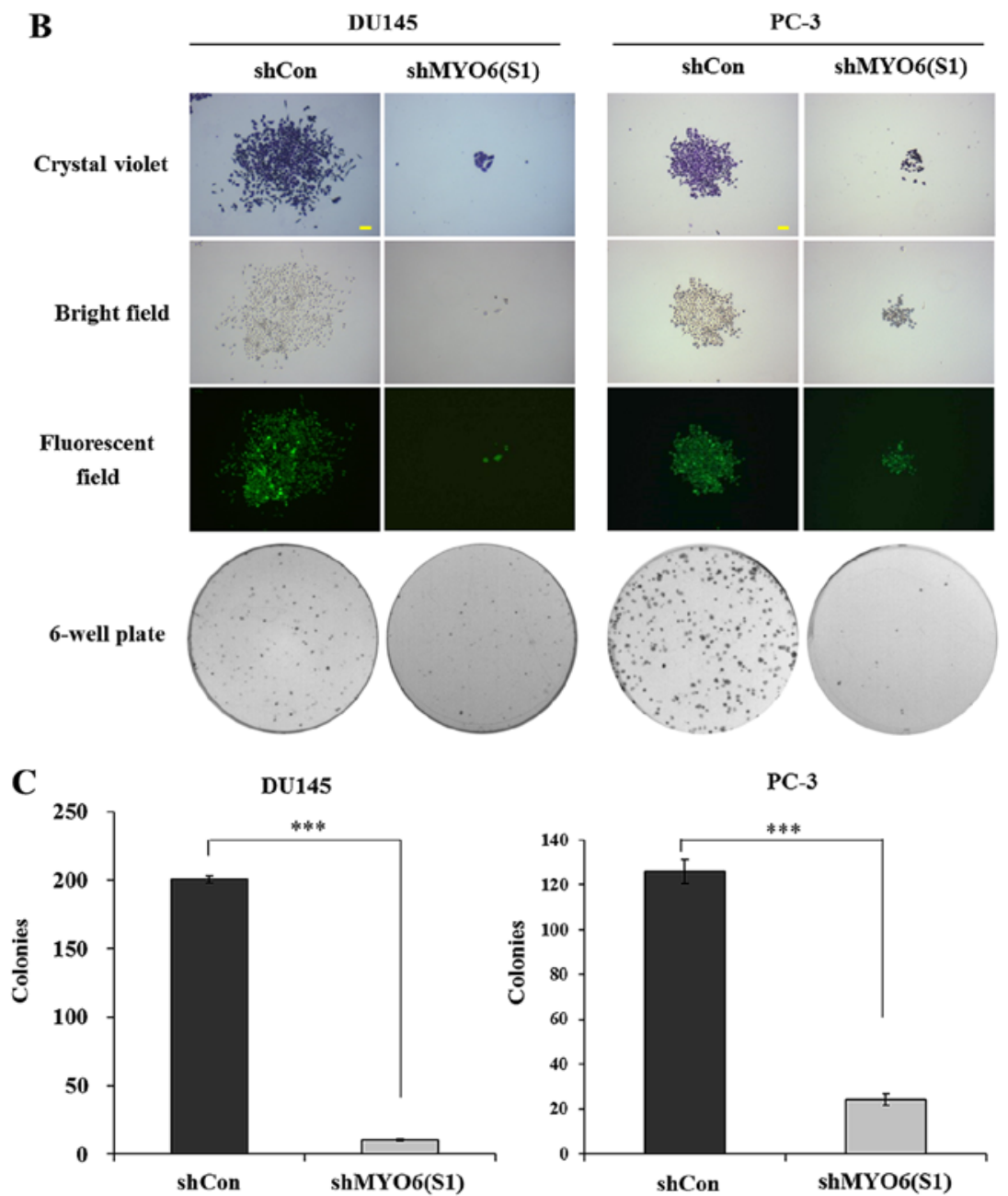

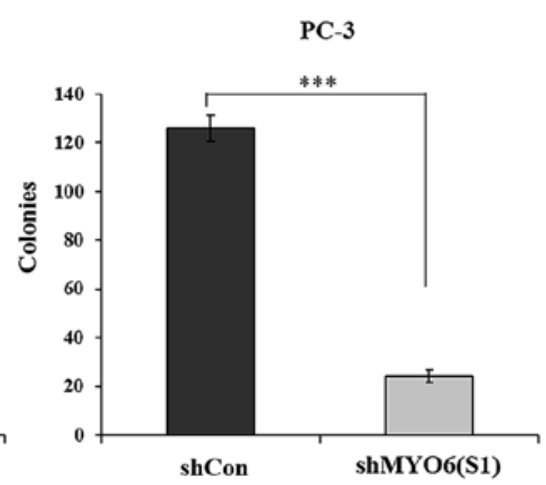

Figure 3. Effects of shMYO6 (S1) on the proliferation of DU145 and PC-3 cells. (A) Cell proliferation was measured by MTT assay. (B) The size and number of colonies in the DU145 and PC-3 cells were recorded under a fluorescence microscope. Representative images shown are from one of three independent experiments. (C) Statistical analysis of colony numbers in the shMYO6 (S1)-treated and shCon-treated cells. Data are presented as mean \pm standard deviation of three independent experiments performed in triplicate. ${ }^{* * *} \mathrm{P}<0.001 \mathrm{vs}$. shCon.

A

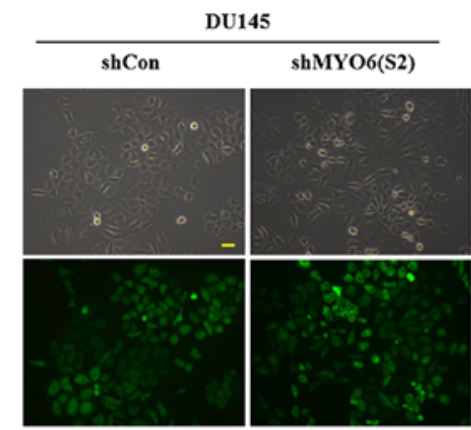

B

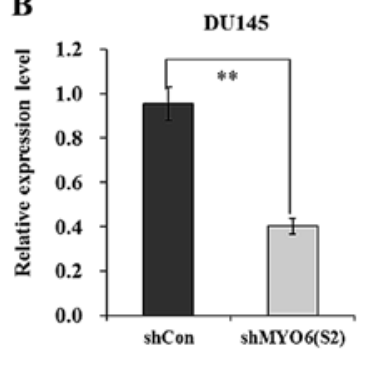

C

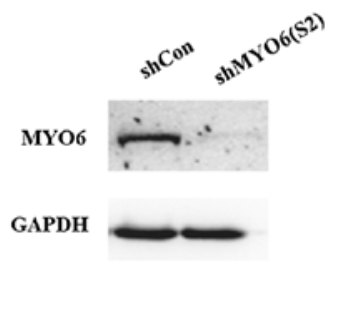

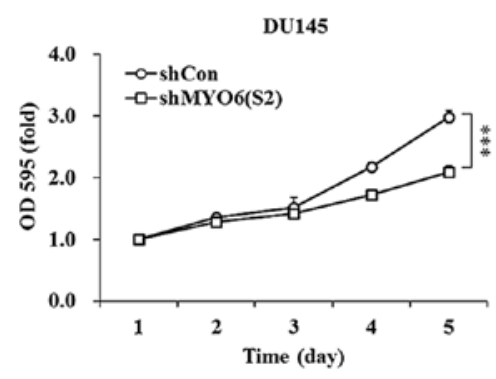

Figure 4. Effects of shMYO6 (S2) on the proliferation of DU145 cells. (A) Represent images of DU145 cells infected with shMYO6 (S2) and shCon for $96 \mathrm{~h}$. (B) shMYO6 (S2) transduction obviously inhibited MYO6 mRNA and protein levels as determined by qRT-PCR and western blot analysis. (C) Knockdown of MYO6 blocked the proliferation of the DU145 cells, as determined by MTT assay. ${ }^{* *} \mathrm{P}<0.01$ and ${ }^{* * *} \mathrm{P}<0.001 \mathrm{vs}$. shCon.

(S1)-treated cells, as determined by western blot analysis. These results indicate that MYO6 knockdown inhibited the growth of prostate cancer cells via blockade of ERK1/2, AKT3, PRAS40 and activation of PARP.

\section{Discussion}

Prostate cancer is one of the most heterogeneous cancers histologically and clinically (16). MYO6 is related to actin 
A
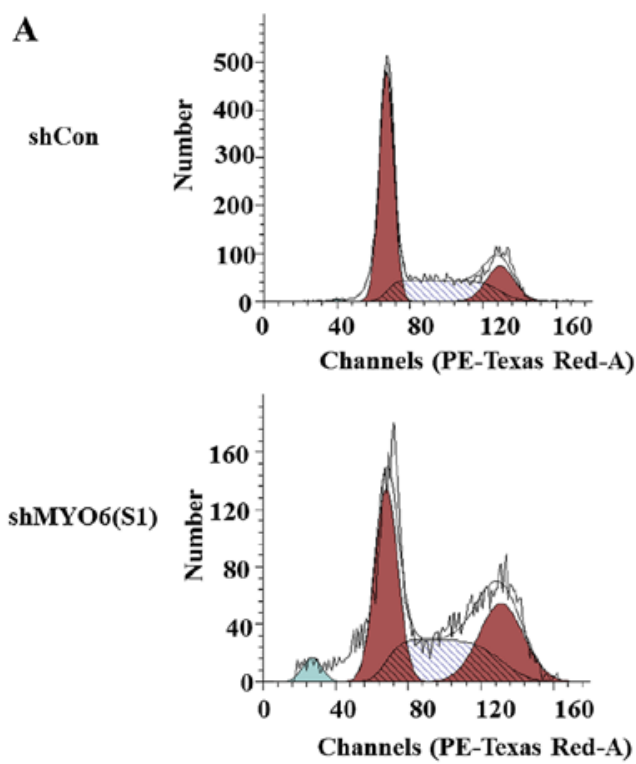

B

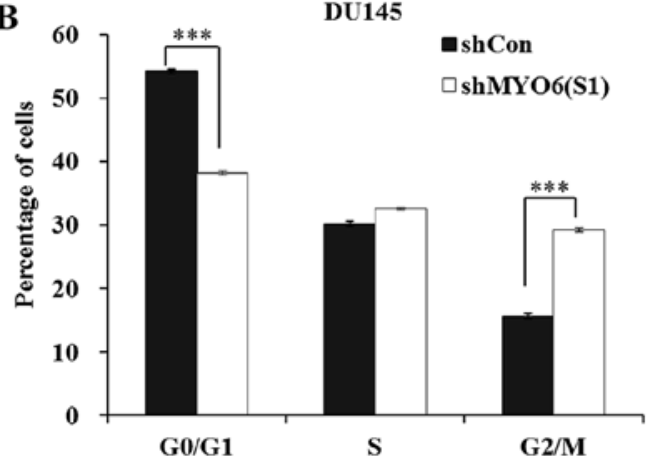

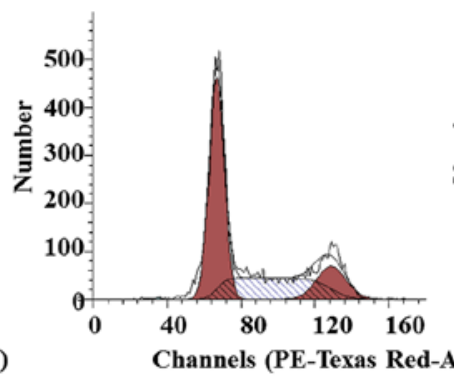
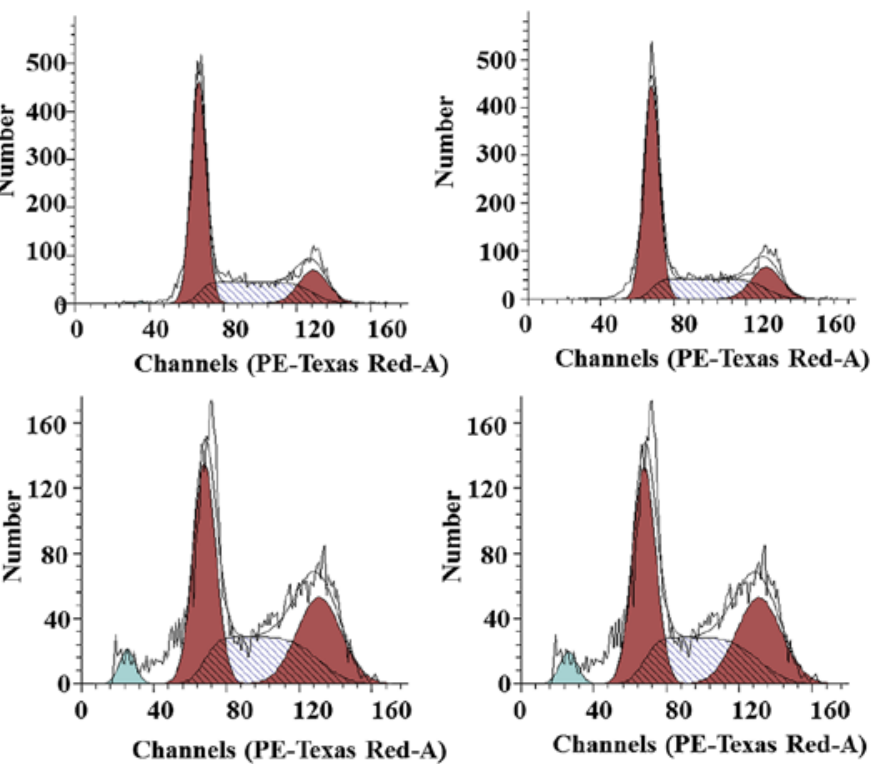

C

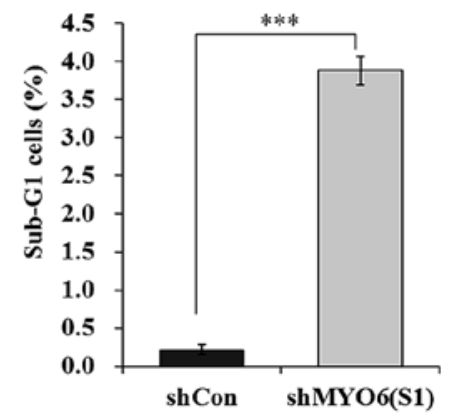

Figure 5. MYO6 knockdown mediated by Lv-shMYO6 (S1) induces G2/M and sub-G1 phase arrest in human prostate cancer DU145 cells. (A) Cell cycle distribution of DU145 cells was determined by flow cytometry. (B) A higher percentage of cells was found at the G2/M phase in the MYO6 (S1)-treated cells than that in the shCon group. (C) The percentage of sub-G1 cell population was significantly higher in the shMYO6 (S1) group compared with the control group. ${ }^{* * *} \mathrm{P}<0.001$.

A

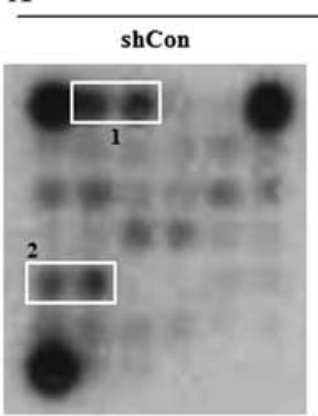

DU145 cells

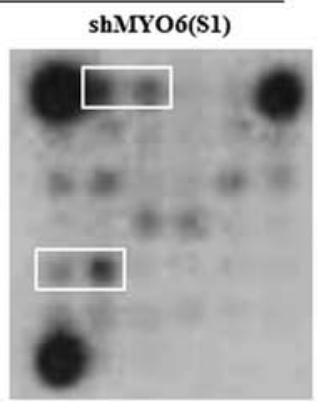

B

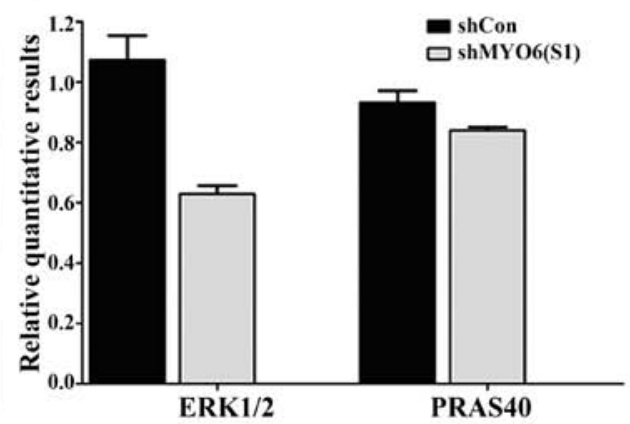

C

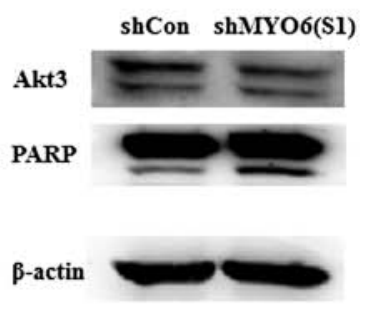

Figure 6. MYO6 knockdown inhibits activation of several cell growth-associated markers and promotes cell apoptosis markers. (A) Typical images of antibody array containing 18 important and well-characterized signaling molecules when phosphorylated. 1 and 2 represent ERK1/2 (Thr202/Tyr204) and PRAS40 (Thr246). (B) Quantitative analysis of molecules that were downregulated in the shMYO6 (S1)-treated DU145 cells using ImageJ software. (C) Western blot analysis showed that knockdown of MYO6 downregulated expression of AKT3 and upregulated expression of PARP.

motor and participates in intracellular vesicle trafficking and transport $(17,18)$. The present study aimed to explore a potential link between MYO6 and prostate cancer. Our results showed that higher expression of MYO6 was found to be significantly related with Gleason score, which indicates that MYO6 is associated with the development of prostate cancer. To further explore the biological function of MYO6 in prostate cancer, the expression of MYO6 was specifically knocked down in two prostate cancer cell lines DU145 and PC-3. Decreased MYO6 expression by two shRNAs both impaired cell proliferation and colony formation. Moreover, the DU145 cells were arrested at the G2/M and sub-G1 phases in response to MYO6 
knockdown. Wang et al previously also observed inhibited cell proliferation and impaired colony formation, as well as G2/M and sub-G1 phase arrest in breast cancer cells after MYO6 silencing (19).

To reveal the molecular mechanisms underlying MYO6-mediated prostate cancer cell proliferation, various signaling molecules involved in cell growth and survival in DU145 cells after MYO6 knockdown were investigated. ERK1/2 is a member of the mitogen-activated protein kinase superfamily, and its phosphorylation through the Ras-RafMEK-ERK (or ERK pathway) signaling network, can regulate cell motility, invasiveness, and apoptosis $(20,21)$. The Ras-RafMEK-ERK pathway is frequently active in cancer through upstream signaling molecule activation to promote human tumor+ development $(22,23)$. In the present study, the ERK1/2 phosphorylation was decreased in prostate cancer cells by MYO6 knockdown. This indicates that the ERK1/2 is a downstream target of MYO6 and the Ras-Raf-MEK-ERK pathway may be suppressed by knockdown of MYO6.

PRAS40 has been shown to be overexpressed in breast and lung cancer cells, indicating that it plays an important role in cancer growth (24). PRAS40 is also a critical downstream protein of the Akt3 signaling cascade and the elevation of PRAS40 phosphorylation facilitates melanoma tumor cell growth $(25,26)$. A previous report also demonstrated that knockdown of PRAS40 and Akt3 protein levels corresponded to increased levels of cleaved caspase-3, which is a marker of apoptosis (25). PARP is one of the most used diagnostic tools for the detection of apoptosis in cells (27). As a specificity substrate, when PARP is cut by the cleavage of caspases, apoptosis will be induced. The present research found that more cells accumulated in the sub-G1 phase. Furthermore, western blot data revealed that PARP was activated and AKT3 was suppressed by MYO6 knockdown. Furthermore, in OVCA429 and DOV13 cells, reduced Akt3 activity was found to lead to marked accumulation of cells in the G2-M phase (28). Notably, the increased PRAS40 phosphorylation paralleled increased Akt3 activity during melanoma cancer development (25). In this investigation, $\mathrm{G} 2 / \mathrm{M}$ arrest was observed in the prostate cancer cells following MYO6 knockdown. This result suggested that Akt3 activity was decreased due to deregulated phosphorylation of PRAS40, which led to prostate cancer cell arrest at the $\mathrm{G} 2 / \mathrm{M}$ phase.

In conclusion, we firstly identified that MYO6 plays an important role in prostate cancer cell growth. It would be important to confirm the oncogenic function of MYO6 in prostate cancer in vivo. Collectively, MYO6 could be considered as a potential therapeutic target for the treatment of prostate cancer.

\section{Acknowledgements}

This work was supported by the National Natural Science Foundation of China (nos. 81272247 and 81372751).

\section{References}

1. Varambally S, Dhanasekaran SM, Zhou M, Barrette TR, Kumar-Sinha C, Sanda MG, Ghosh D, Pienta KJ, Sewalt RG, Otte AP, et al: The polycomb group protein EZH2 is involved in progression of prostate cancer. Nature 419: 624-629, 2002.
2. Hsing AW, Tsao L and Devesa SS: International trends and patterns of prostate cancer incidence and mortality. Int $\mathrm{J}$ Cancer 85: 60-67, 2000.

3. Wolk A, Andersson SO and Bergström R: Prospective study of sex hormone levels and risk of prostate cancer. J Natl Cancer Inst 89: 820, 1997.

4. Visakorpi T, Kallioniemi AH, Syvänen AC, Hyytinen ER, Karhu R, Tammela T, Isola JJ and Kallioniemi OP: Genetic changes in primary and recurrent prostate cancer by comparative genomic hybridization. Cancer Res 55: 342-347, 1995.

5. Lu W, Singh AK, Khan SA, Senapati D, Yu H and Ray PC: Gold nano-popcorn-based targeted diagnosis, nanotherapy treatment, and in situ monitoring of photothermal therapy response of prostate cancer cells using surface-enhanced Raman spectroscopy. J Am Chem Soc 132: 18103-18114, 2010.

6. Jung EJ, Liu G, Zhou W and Chen X: Myosin VI is a mediator of the p53-dependent cell survival pathway. Mol Cell Biol 26: 2175-2186, 2006.

7. Vale RD: Switches, latches, and amplifiers: Common themes of G proteins and molecular motors. J Cell Biol 135: 291-302, 1996.

8. Homma K, Yoshimura M, Saito J, Ikebe R and Ikebe M: The core of the motor domain determines the direction of myosin movement. Nature 412: 831-834, 2001.

9. Buss F, Spudich G and Kendrick-Jones J: Myosin VI: Cellular functions and motor properties. Annu Rev Cell Dev Biol 20: 649-676, 2004

10. Szczyrba J, Löprich E, Wach S, Jung V, Unteregger G, Barth S, Grobholz R, Wieland W, Stöhr R, Hartmann A, et al: The microRNA profile of prostate carcinoma obtained by deep sequencing. Mol Cancer Res 8: 529-538, 2010.

11. Morille M, Passirani C, Vonarbourg A, Clavreul A and Benoit JP: Progress in developing cationic vectors for non-viral systemic gene therapy against cancer. Biomaterials 29: 3477-3496, 2008.

12. Dunn TA, Chen S, Faith DA, Hicks JL, Platz EA, Chen Y, Ewing CM, Sauvageot J, Isaacs WB, De Marzo AM, et al: A novel role of myosin VI in human prostate cancer. Am J Pathol 169: 1843-1854, 2006.

13. Yoshida H, Cheng W, Hung J, Montell D, Geisbrecht E, Rosen D, Liu $\mathrm{J}$ and Naora $\mathrm{H}$ : Lessons from border cell migration in the Drosophila ovary: A role for myosin VI in dissemination of human ovarian cancer. Proc Natl Acad Sci USA 101: 8144-8149, 2004.

14. Puri C, Chibalina MV, Arden SD, Kruppa AJ, Kendrick-Jones J and Buss F: Overexpression of myosin VI in prostate cancer cells enhances PSA and VEGF secretion, but has no effect on endocytosis. Oncogene 29: 188-200, 2010.

15. Fernandes BF, Odashiro AN, Saraiva VS, Logan P, Antecka E and Burnier MN Jr: Immunohistochemical expression of melan-A and tyrosinase in uveal melanoma. J Carcinog 6: 6, 2007.

16. Singh D, Febbo PG, Ross K, Jackson DG, Manola J, Ladd C, Tamayo P, Renshaw AA, D'Amico AV, Richie JP, et al: Gene expression correlates of clinical prostate cancer behavior. Cancer Cell 1: 203-209, 2002.

17. Demichelis F, Setlur SR, Beroukhim R, Perner S, Korbel JO, Lafargue CJ, Pflueger D, Pina C, Hofer MD, Sboner A, et al: Distinct genomic aberrations associated with ERG rearranged prostate cancer. Genes Chromosomes Cancer 48: 366-380, 2009.

18. Santos JI, Teixeira AL, Dias F, Gomes M, Nogueira A, Assis J and Medeiros R: Restoring TGF $\beta 1$ pathway-related microRNAs: Possible impact in metastatic prostate cancer development. Tumour Biol 35: 6245-6253, 2014.

19. Wang H, Wang B, Zhu W and Yang Z: Lentivirus-mediated knockdown of myosin VI inhibits cell proliferation of breast cancer cell. Cancer Biother Radiopharm 30: 330-335, 2015.

20. Mebratu Y and Tesfaigzi Y: How ERK1/2 activation controls cell proliferation and cell death: Is subcellular localization the answer? Cell Cycle 8: 1168-1175, 2009.

21. Shin SY, Rath O, Choo SM, Fee F, McFerran B, Kolch W and Cho KH: Positive- and negative-feedback regulations coordinate the dynamic behavior of the Ras-Raf-MEK-ERK signal transduction pathway. J Cell Sci 122: 425-435, 2009.

22. McCubrey JA, Steelman LS, Chappell WH, Abrams SL, Franklin RA, Montalto G, Cervello M, Libra M, Candido S, Malaponte G, et al: Ras/Raf/MEK/ERK and PI3K/PTEN/Akt/ mTOR cascade inhibitors: How mutations can result in therapy resistance and how to overcome resistance. Oncotarget 3: 1068-1111, 2012.

23. Armin Z, Czernilofsky AP, Gy?Rgy K, Julja S, Heinz S and Jakob T: Signaling through RAS-RAF-MEK-ERK: From basics to bedside. Curr Med Chem 14: 601-623, 2007. 
24. Huang B and Porter G: Expression of proline-rich Akt-substrate PRAS40 in cell survival pathway and carcinogenesis. Acta Pharmacol Sin 26: 1253-1258, 2005.

25. Madhunapantula SV, Sharma A and Robertson GP: PRAS40 deregulates apoptosis in malignant melanoma. Cancer Res 67: 3626-3636, 2007.

26. Sharma A, Sharma AK, Madhunapantula SV, Desai D, Huh SJ, Mosca P, Amin S and Robertson GP: Targeting Akt3 signaling in malignant melanoma using isoselenocyanates. Clin Cancer Res 15: 1674-1685, 2009.
27. Bressenot A, Marchal S, Bezdetnaya L, Garrier J, Guillemin F and Plenat F: Assessment of apoptosis by immunohistochemistry to active caspase-3, active caspase-7, or cleaved PARP in monolayer cells and spheroid and subcutaneous xenografts of human carcinoma. J Histochem Cytochem 57: 289-300, 2009.

28. Cristiano BE, Chan JC, Hannan KM, Lundie NA, Marmy-Conus NJ, Campbell IG, Phillips WA, Robbie M, Hannan RD and Pearson RB: A specific role for AKT3 in the genesis of ovarian cancer through modulation of $\mathrm{G}(2)-\mathrm{M}$ phase transition. Cancer Res 66: 11718-11725, 2006 